\title{
The Vernacular Roots Vernacular Architecture as a Leader to the New Sustainable Dwelling
}

\author{
Vanessa Flaiban ${ }^{1}$ \\ Master Degree of Architecture \\ FHNW Basel \\ Germany \\ vflaiban@gmx.ch
}

\begin{abstract}
In today's world, sustainability is gaining importance primarily in architecture; it should be possible to build it sustainably in the tropics. An example of this is the vernacular architecture, local materials and an adaptation to the environment, which enable the design of outstanding dwellings, which do not rely on technical tools. Unfortunately there is a great imbalance in Bali, and the local population is still strongly dependent on the building of the vernacular. The tourism industry has created its own high-tech architecture. Apart from a few exceptions, the luxury tourism industry nowadays has to deal with climatic factors instead of adapting them. Now I would like to research in a case study which aspects make the Balinese house so adapted and whether these aspects are still valid for today's claims. Basically, I asked myself these four questions: What are the characteristics of a contemporary tropical house in Bali? What aspects make these houses a tropical house without a negative impact on the Balinese vernacular architecture? What architectural means can help to create a local identity? Which architectural instrument makes it possible to integrate into Balinese urbanity? I would like to try to answer these questions using the case study of two examples and my gained knowledge.
\end{abstract}

Index Terms-

\section{INTRODUCTION}

At the beginning of this paper, I will define precisely the problems and my questions. In my opinion, there is an architectural imbalance in Bali. There are enormous opposites between the houses of the Balinese population and the buildings built for tourism. In general opposites and a great variety in urbanism and architecture creates an interesting tension, which characterizes the local identity. What I would like to address is that I have noticed how simple rules have developed extremely good habitations for this hot, humid climate. These can completely dispense with air-conditioning and high-tech, since the vernacular architecture never had the possibility to rely on such hightech products. The local architecture is mainly focused on the simple habitations of the local population. The inclusion of the climatic factors has always been of great importance for the construction of the vernacular buildings, as opposed to the stately buildings. This buildings which had access to the technical facilities thanks to financial means, could partly ignore the climatic factors[1]. This refers to the local building and the relationship to the climate in Europe, but the same observation I do here in Bali. The local population, with its traditional architecture, follows the example of vernacular construction. The tourism sector, with its villas and hotel buildings, which I see as a stately architecture, can escape due to financial resources, any climatic factors. Since many years, the problem of sustainability and construction material shortage has been a 
major issue on a global scale. It is a mystery to me how the tourism sector, which could have the resources and the knowledge, no longer focuses on this. The traditional Indonesian building culture is, in my opinion, an excellent example of sustainable construction, thanks to its natural materials and the inclusion of climatic factors.

The vernacular architecture does not live on the artistic work of an architect or designer, but rather that it meets the basic needs of a person and his environment. The house could be viewed as the third skin of human, which has the function to breathe and react to his environment. However, if the house is regarded as an unstable matter, a climatecompensating machine must be installed in it [2]. Even if this is a temporary home, the human being has the same basic needs as in his usual environment. Unfortunately this seems to be a rarity here in Bali. IBUKU and Popo Danes are great examples in this area and both try to influence the tourist industry in their own individual way. The reaction to the environment and the climate creates a localized and specific architecture, which can generally dispense with ornaments and embellishments. I noticed that many of the tourist buildings, try to adapt to the local buildings with the help of the typical decorations. In general, the Balinese house is already decorated with many ornaments, if you leave it out, a clear and very simple structure of the individual pavilions and their use is determined. A repeating support grid and a clear structure between the base, shank and roof as well as the type of construction and the materials have a recognition value, which makes this architecture so unique.

The contemporary tropical home is defined as being based on low-tech, thanks to its urban location, the materials and construction as well as by its modification to the climatic factors. It is perfectly adapted to the hot humid climate and finds inspiration in vernacular and indigenous architecture. In contrast to the vernacular buildings are the villas, which cannot do without technology and airconditioning. Often small villages are located on the outskirts of the tourist centers, where a villa residential can be found next to one another. Often agricultural areas and the local population are displaced for giving space to this buildings. Unfortunately, the residential buildings of the local inhabitants are losing their traditional architectural style. The faster and easier way to build, which the concrete brings with it, replaces regional materials and the building knowledge. The prefabricated trusses of aluminum displace the complex and elaborate timber construction. The technical possibilities with light and power supply, lead to the construction no longer be adapt to the climate, but follow the current fashion or the wish of the builder.

On the basis of these observations and the starting point defined by me, I would like to answer these questions in the further approach:

a. What are the characteristics of a contemporary tropical house in Bali? b. What aspects make these houses a tropical house without a negative impact on the Balinese vernacular architecture?

c. What architectural means can help to create a local identity?

d. Which architectural instrument makes it possible to integrate into Balinese urbanity?

I hope to answer the questions, which I have defined in the discussion of the initial situation, in which I study the Indonesian vernacular architecture and a contemporary tropical architectural example. I will do two case studies and try to define them in their technical, cultural and urban characteristics. The Balinese property will serve as a first example in the field of vernacular architecture. Since my problems and observations are mainly related to Bali, it is important for me to understand how the local architecture works. For the contemporary example, I chose the MarikaAlderton house by Glenn Murcutt. In my opinion, this building is an excellent example of contemporary architecture that deals with the place and its climate. The climate is a major design factor in this project. I will divide my research aspects in three categories:

- Technical characteristics

- Cultural characteristics

- Urban development

To the technical characteristics I will count the materiality, construction as well as the climate specific characteristics. The cultural characteristics are defined by specific places for rites and religious ceremonies. Among other things, the topics of the community, in my opinion family and everyday life have to be considered as well. I would like to deal with aspects, orientation and location as well as landscape, environment and urban structure for the urban characteristics.

In a further step, I will compare the acquired knowledge to define primarily similarities, which are decisive for the design of a location-specific, climate-adapted and sustainable architecture. In the last part of this paper, I will try to project the results from the case study and the comparison to the local identity. I would like to point out that the recognition value has nothing to do with ornament and decoration, but that it is created as soon as a building is adapted to its surroundings, regarding material, orientation, location and climate. Finally, I would like to conclude, with the developed knowledge, to answer the questions defined in the initial situation.

\section{Case Study}

As I said, I will make a case study on two buildings. In the first case study I would like to examine the important characteristics of the Balinese House. In the second study I will dedicate myself to the contemporary example of Glenn Murcutt's design. 


\section{Definition of the Balinese House}

The home also called Umah, consists of several small buildings called Bale, which are located in a walled estate. (fig. 1) The layout of the buildings as well as their implementation is assigned to various uses. The Bale are grouped around the open courtyard called Natah. The walled family shrine is located at the northeast corner of the property. Each Bale is assigned one or more uses, which I would briefly explain in the next section.

The Balinese House consists of the following pavilions: The Bale Daja, the north pavilion is used as a sleepinghouse and storage space for family treasures, it serves the parents and the unmarried daughters as a bedroom. The pavilion consists of eight columns and has four brick walls, and it is the only pavilion, which can be completely closed. The room is often windowless, the only access and light source, is the centrally placed entrance. A small veranda is located at the front, which is directed towards the inner courtyard. The Bale Delod of the south pavilion is a multifunctional building located centrally on the property facing north. It serves various purposes, for example, it is used for most religious ceremonies or to guests receiving. This building is formed by six, eight or twelve pillars and is closed at least on the back with a wall. The Bale Dangin serves the grandparents as a bedroom; it is located in the east and faces west. This Bale is closed on two or three sides with a brick wall. The Bale Dauh is located in the west and serves the unmarried boys as a bedroom. The pavilion can be closed like the Bale of the parents or partly as open as the pavilion in the east. It is directed towards the east and the inner courtyard. If it is closed, a porch is placed in front of it. The Paon, the kitchen, is located in the southwest of the property. The size is typically about $3.40 \times 2.65$ meters and it is closed on three sides with walls and opens to the north. This building is used exclusively for cooking. The granary also called Jineng is used for the storage of the rice. Usually it is the only building, which stands on pillars to safe the rice from the insects and rats. This pavilion is placed southeast on the estate. The entrance gate Pemesuan and the surrounding wall Penyengker are additionally important components of the Balinese house [3].

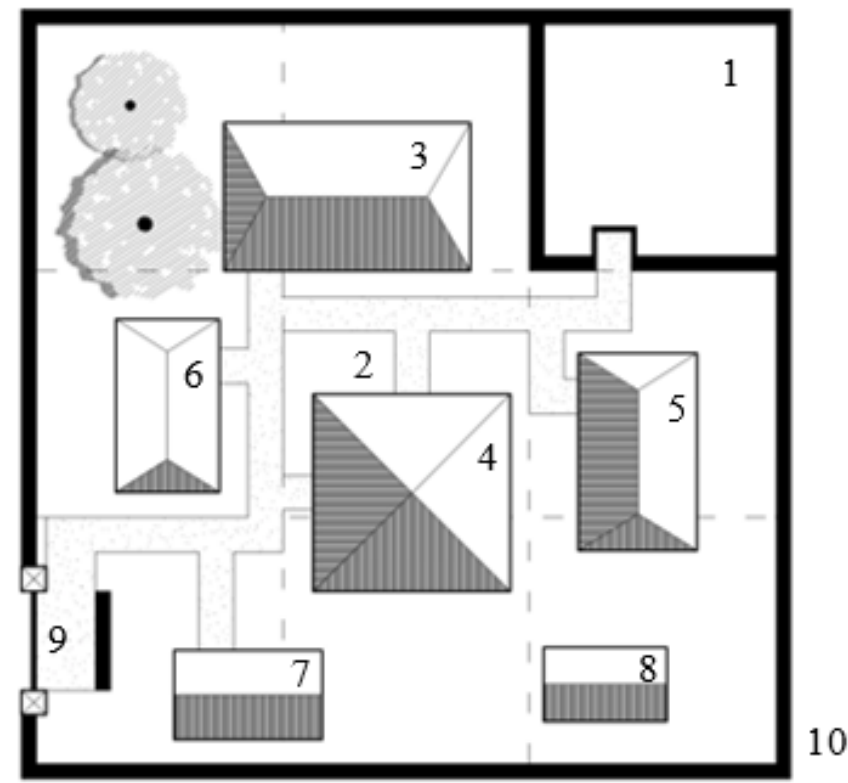

The balinese house

1. Sanggah (Family shrine)

2. Natah (inner courtyard)

3. Bale Daja (parents bedroom)

4. Bale Delod (rituals and guests)

5. Bale Dangin (grandparents bedroom)

6. Bale Dauh (boys bedroom)

7. Paon (kitchen)

8. Jineng (granary)

9. Pemesuan (gate)

10. Penyengker (surrounding wall)

\section{A. Technical characteristics.}

Traditionally, natural and local materials are used for the dwellings. The traditional material for the roof is in this case thatch. The traditional thatched roof consists of the Alang-Alang grass. It is superimposed in many layers and produces thick, soft roofs. Wood shingle made of bamboo or other wood and tiles are also used to cover the roof.

The most common materials for walls are bricks or bricks made of sandstone. The sandstone is easy to process since it is very soft and it is particularly popular for ornaments.

The columns are made of wood, but there are woods that are more or less suitable for this purpose. The foundations as well as the base of the pavilion are from red brick, sandstone, river stones or concrete. It is also possible to use demolition material from other buildings [3].

The construction of the Bale is reflected in a simple and clear structure. In the vernacular architecture, certain types of construction have developed from the availability of the materials and their possibility to process them. The construction and structure is clearly visible and rarely hidden behind panels. The Balinese pavilion consists of a masonry base, which is slightly elevated from the rest of the area. The base usually corresponds to the size of the overhanging roof. The roof is supported by pillars, the walls surrounding the pavilion are detached from the supporting 
structure and form an exclusively enclosing function in the construction and no load bearing [3].

The complex wooden truss is located on a wooden frame, which is supported by the columns. There are three usual roof forms the pyramid roof, the hipped roof or pitched roof. The roof trusses are often very complex and multi-part because the whole construction consists of a plug system and practically no nail or screw are used. The construction is usually shown open in the room; the underside of the roof skin may be covered with bamboo mats or other wickerwork. For the walls, the preferred building material is Paras, a kind of soft sandstone cut into uniform brick blocks and then dried in the sun. These bricks are moistened with only very little mortar, almost only water and then stacked on top of each other and rubbed together again and again until they stick firmly together. Paras is very soft and can be easily carved and is often used for ornaments, it is unfortunately not very long lasting when exposed to the elements. Therefore, it often needs to be renewed [4].

\section{B. Cultural characteristics}

The cultural characteristics are very complex in the example of the Balinese house, I will not be able to deal with all the spiritual and religious specialties, so I would like to focus specifically on the Tre-Angga concept and the ideology of the microcosm and macrocosm.

\section{Origin of the Balinese Hinduism}

The Balinese Hinduism originates in the Majapahit dynasty, which dominated from Java in the 14th and 16th centuries, the largest parts of the Indonesian Archipelago. Their politics and religion were very much influenced by Indian Hinduism and Buddhism. At the end of the 15th century, this culture became a Muslim society. The scholars and priests fled to Bali, where they could live their religion and culture. This mixed strongly with the indigenous animism and even more with Buddhism and thus arose the unique Balinese Hinduism [4].

\section{Microcosm and macrocosm}

Balinese architecture is based on a metaphysics that sees the universe as a whole. In this group each part has its participation in the existence of another part and the microcosm is perceived as a reflection of the macrocosm.

The precise orientation in space, as well as the idea of purity and pollution, are important aspects to bring harmony between man and the rest of the universe. This world view results from the Hindu idea of a divine cosmic order (dharma) originated from a much older animistic tradition [4].

\section{E. Tre-Angga}

The ideology of the tripartism, in the Balinese culture, divides all natural and man-made into three parts: nista, madya and utama. Utama means "above" or "high" and refers to the mountains, where the gods dwell, it describes the sky the place of the ancestors, and denotes all that is pure and holy. Nista is the opposite and refers to things that are "low" or "down", it refers to the sea, the place of evil spirits, and is equivalent to hell, the dead, the unclean and profane. Madya refers to that in between, the world of human. In the same principle, the human body is divided into three parts, feet, torso and head. The top element is the holiest, it is also not liked to see when people are attached to the head, the torso as a neutral middle part and the feet as the bottom profane element. The feet should neither be directed against persons nor is it gladly seen if one puts them somewhere, so that they are, for example, higher than the head. The same principle can also be applied to architecture. The base as Nista, the shaft is seen as Madya and the roof is considered the holiest [4].

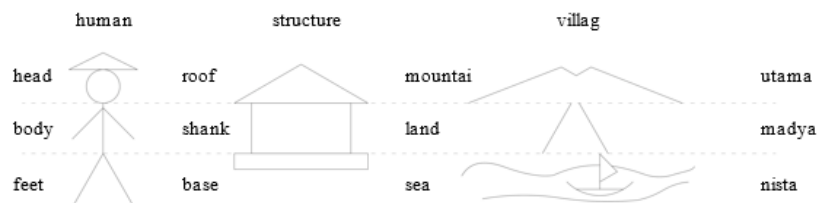

From these two basic ideologies of Balinese culture, derives a very specific sense of the right place. It is clearly defined that man has his stay between the divine on the mountain and the evil spirits in the sea. This idea can also be explained by the positioning of the buildings in the Balinese property. In order to balance the universe, it must be ensured that everyone has the right place and orientation. Positioning against the rest of the world is here particularly important. The two main directions are Kaja and Kelod. Kaja means "towards the mountains" and refers to the divine and Kelod "to the sea" denotes the direction to the evil spirits [4].

This explains the exact arrangement of the buildings, the most sacred place is the family temple. All secular things, such as trash and toilets, have their place on the opposite side.

\section{THE ARCHITECT GLENN MuRCUTt AND THE MARIKA- ALDERTON HOUSE}

My second case study will be about the Marika-Alderton house of Glenn Murcutt.

Who is Glen Murcutt? A brief summary of his biography will give me a better insight into his thinking and work. Then I will dedicate myself to the Marika-Alderston house, I will make a brief description of the house, before I examine it according to the defined aspects.

\section{A. The architect Glenn Murcutt and The Marika-Alderton House}

The Australian was born in London 1936 during a trip of his parents in England. He spent his childhood in Papua New Guinea, where he learned a lot about vernacular building by his father.

He completed his architectural studies at the Technical College of the University of New South Wales. Since the 1970s, he has run his own architecture office. He has decided to work out small projects as he thinks he has much 
more opportunities to experiment on a smaller scale. His projects are located exclusively in Australia. In 2002 he was awarded the Pritzker Prize [4].

\section{B. The Marika-Alderton House}

The house was planned and built between 1991 and 1994. It is located $3 \mathrm{~m}$ above sea level in Eastern Arnhem Land. Australia's Northern Territory, which is part of the Yirrkala land belonging to the Aborigines, a special cultural environment for this project. This region of Australia is characterized by a tropical climate. As in my previous definition of the climate, the region is dominated by monsoon, which primarily involves two seasons, wet, hot summers and dry winters, with about the same temperature. The building is located just off a suburban settlement, at a river mouth, freshwater lagoon and in the immediate vicinity of the sea. The whole area is subject to regular seasonal flooding. The subsoil is primarily very sandy and has a good drainage. The volume of the house is narrow and long. The building consists of several steel frames, which are filled with timber panels and solid wood panels. This house consists of a platform and has a pitched roof, with very deep eaves. The roof is covered with a corrugated iron, the windows can be closed with wooden lamellas or wood panels but are not closed by glass. The southern façade is very striking with its pinned wooden boxes, which mark the installation furniture and sleeping niche. The entire wooden structure seems to be involved in the primary steel structure. The ground plan is reminiscent of a long house, in the east is located the living room and the kitchen, followed by the bedrooms, at the end of the building is the main bedroom arranged. The hallway is located along the northern facade, and the bathroom is installed between the rooms and the corridor.

"Layering and changeability: this is the key, the combination that is worked into most of my buildings. Occupying one of these buildings is like sailing a yacht; you modify and manipulate its form and skin according to seasonal conditions and natural elements, and work with these to maximize the performance of the building." - Glenn Murcutt, 1996
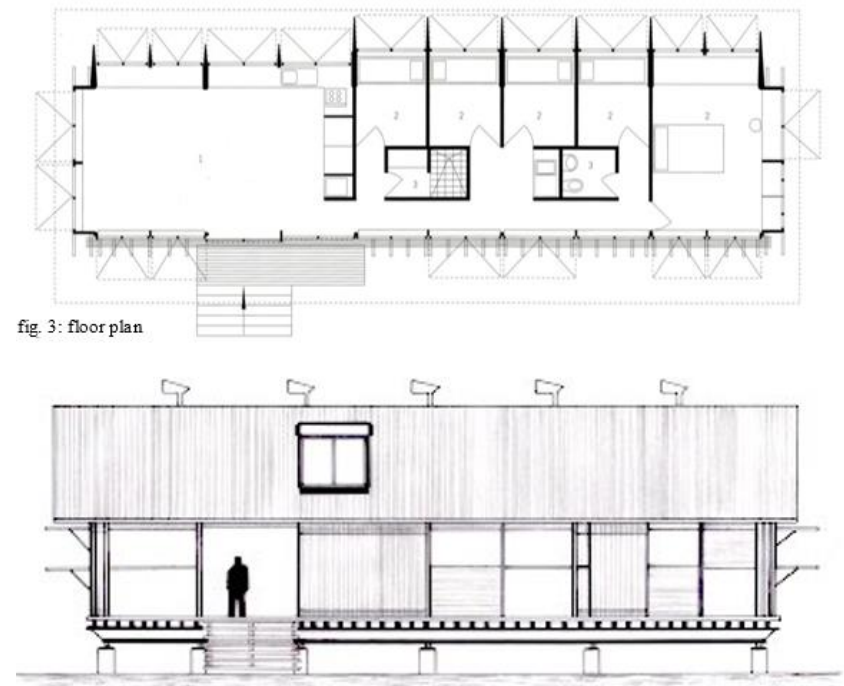

fig. 4: elevation north
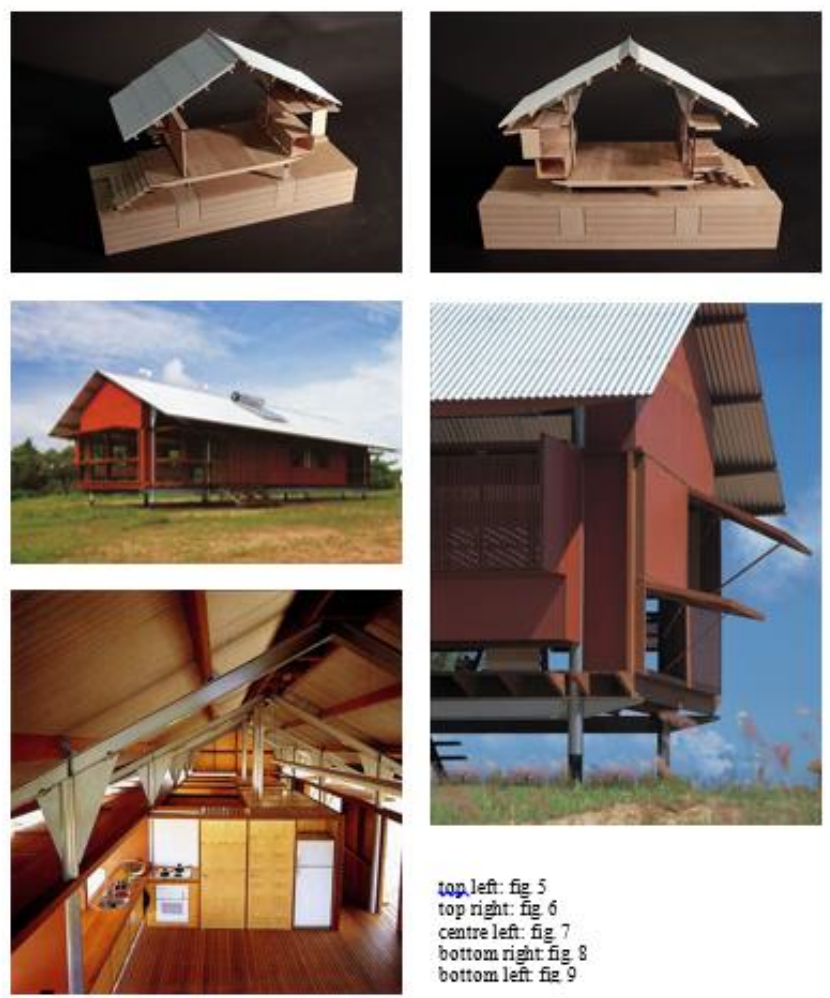

C. Technical Characteristics

The building consists of materials that have low thermal capacity. The light construction and materials save less heat and the building can cool down at night. The house consists mainly of wood and metal, which were only assembled as prefabricated parts on site. The use of very few different materials creates a very uniform image of the architecture.

The relatively simple construction with the help of the metal frame, allows to build a large room height with an open roof. The floor plan is clearly structured and designed in such a way that cross ventilation is possible. (fig.10)

The architect attaches great importance to climatic factors, which makes them very visible. The house stands elevated on a pillar, which are building a base. The fact that the 
house is not situated directly on the ground protects the construction during floods and lets the fresh air flow through under the building. (fig.11) there are countless ways to open the windows, most of the openings are with slats or wooden doors, which can be individually opened or closed. I particularly like the openings directly above the floor, these generates an airflow, which rises upwards to the roof, where provided air slots, let the hot air escape over it. (fig. 12) By opening the wooden doors to the outside, a shadow effect is generated, this could be compared with a front porch, so that no sunlight reaches directly to the house wall. This fact makes the air around the house always cool and helps to reach a good thermal comfort inside. (fig.13) the layout and height of the room, leaves the roof construction completely open, so that the warm rising air will always escape and not held back. The large overhanging roof protects the vertical surfaces from the climatic influences such as rain and direct sunlight. (fig.14) Due to the moving surface of the roof skin, it shadows itself and there is no smooth surface, which can be heated too much by the sun. The location of the house, by the proximity to the water and the immediate proximity of trees and plants, promotes a positive wind flow, by the evaporation of the water and the shadows generated by the trees.(fig. 15,16) In my opinion the building can be classified as sustainable, the wood comes from Australia, the metal is recyclable and the current for the hot water is won over a solar panel.

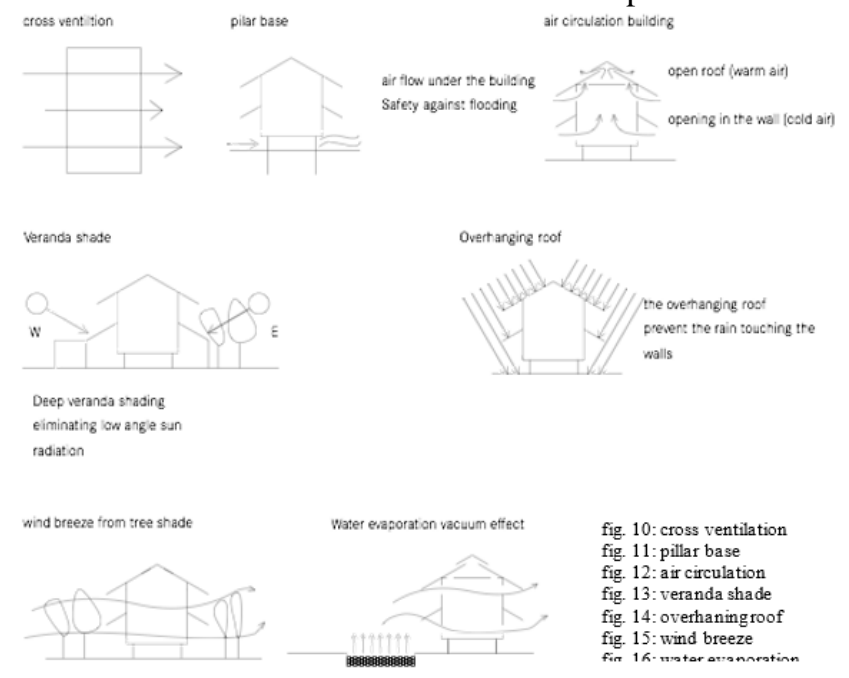

\section{Cultural characteristics}

The western lifestyle is clearly visible in this floor plan, a third of the area is awarded to the living room with kitchen. This seems in Western culture a particularly important meeting place. Here the Family cooks, and came together for the meals as well as guests will be received. The remaining area is occupied by individual bedrooms, for each bed there is a single room. There is also a large bedroom with a double bed, which is used exclusively by the parents. The shower and toilet are placed in the center of the building. There are no special places for religious ceremonies or rites.

\section{E. Urban development}

Since this building has no urban context and not in an immediate proximity to other buildings, it is particularly difficult in this case to address the urban properties. I would rather call it a very adapted setting in a natural environment, with the awareness of climate and nature.

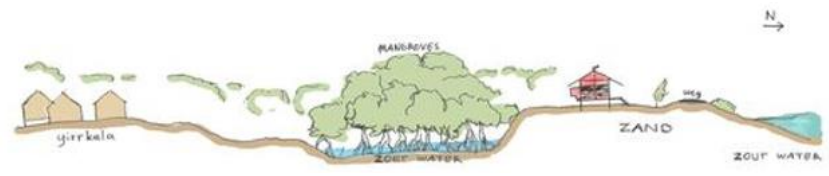

Fig. location and site of the Marika-Alderton house

\section{COMPARISON}

Thanks to the acquired knowledge of the Balinese house and the house of Glenn Murcutt, I will compare the two in this section. It seems to me that it is particularly important to look at the similarities and differences. The vernacular building brings many sustainable aspects and the typical local-identity, which is often lost in contemporary building, because of the financial resources and technological capability. After examining the two case studies, it is noticeable to me that Glen Murcutt had a lot of influence from the vernacular architecture. Both case studies have developed an local-identity because they are adapted to their environment and users.

There can be many similarities seen primarily in the technical characteristics, both working with locally available materials, the mainly used material is wood. The Balinese house relies on bricks to close their pavilions, but the entire structure is made of wood. Glenn Murcutt's work is slightly different, the basic structure is made of metal, but the closing elements are made of wood. In both projects, the simple and clear design, which generates the ideal proportions of space, is clearly visible. Both work with an open saddle roof, which ensures a good room height. Both have an inclined overhanging roof with a low eaves.

An interesting aspect in both projects and for me rather something strange, the windowless buildings. In principle, they are not windowless, primarily by Glenn Murcutt not, but the openings can be completely closed with wood panels or opened and are not sealed with glass panes, as I know from the temperate climatic zone. In the Balinese house, there are these types of openings as well, or there are pavilions which are completely open.

Another striking aspect seems to me is that both types of buildings are very adapted to the tropical climate, the natural ventilation is given by different characteristics. Both types stand on a raised base, in the first case study is the base of stone, which is probably due to the availability of the material. Both types, however, have the same advantages, protection against flooding and cooling of the soil once via air flow and the other time over the soil temperature. As much shade as possible around the building guarantees that the construction does not heat up and a pleasant indoor climate remains in the interior. 
The cultural characteristics are primarily recognizable in the layout plan of the buildings, the contemporary example is influenced by the western lifestyle, whereas the Balinese living culture is different. The house consists of several buildings, not all uses under one roof like Glenn Murcutt did. The bedrooms are more oriented towards user groups than to the individual. Kitchen and bathroom are separate from the remaining living rooms. The kitchen and the living room do not form a spatial unit as we know from the western culture. There is no ritual or religious place in the house or on the property.

The town-planning comparison is a bit difficult for me. Balinese urban development is clearly marked by its strong culture and religion. At the Marika-Alderton house, the orientation and adaptation to the surroundings has a great importance, more than the interaction with other buildings, like in urban areas.

I find it striking that the two structures are very much reflective of their surroundings and thus create an identity which can only arise through their adaptation to the circumstances.

Unfortunately, in my opinion these qualities are missing in tourist accommodations. In most cases, these look more like oversized pavilions, which are reminiscent of the Balinese house. They are mixed with the western standards for the visitors. This is the result of buildings which, although they are similar in appearance to the vernacular, have taken over the roof form and materials, but their climatic adjustment has been lost because the buildings have been completely closed and windows have been installed, or because of complex room arrangements. Since these buildings are generally distant from their models in size and form, they are a foreign object in the urban structure.

\section{Conclusion}

In this conclusion, I will try to answer the questions which I have defined in the initial situation.

a. What are the characteristics of a contemporary tropical house in Bali?

Contemporary home in Bali, must be primarily sustainable, resort to local materials, adapt to its environment in orientation and the climate. It seems to me important, that the precise orientation of a building and the observance of the climatic factors can create a comfortable living environment, which means that there is no technical equipment such as air conditioning needed. Choosing local material will help shorten the transport routes. If the climate is considered as a factor in designing, very clear architectural elements will arise, such as the saddle roof with a low profile eaves or a front porch. The layout plan must allow the building to air through, and this aspect often creates clear structures which clearly define the design in its architectural expression. It is striking that both buildings are one-storied. From this I conclude that the two- or multi- story of a building in the tropical climate is rather a disadvantage.

b. What aspects make these houses a tropical house without a negative impact on the Balinese vernacular architecture?

I am convinced that if certain cultural characteristics, like the ideology of Tre-Angga and the associated order factors, are followed. No one would place the bathroom in the holiest place, which is intended for the family temple, so there would be no cultural conflicts. If the architect chooses local materials and constructions, he deals with the climatic conditions and observes them in his design, each contemporary building will be integrated into the Balinese environment.

c. What architectural means can help to create an local identity?

The place-bound identity is created primarily by the architect, dealing with the environment, including the building culture, the materials, people and landscape. When a building is connected with all these aspects in the best possible way, it creates a local identity.

d. Which architectural instrument makes it possible to integrate into Balinese urbanity?

The Balinese village structure corresponds to the different ideologies of local Hinduism, but as more and more space is needed, a lot of agricultural land is displaced. In this case, I would try to preserve the principle of village structure and to fill the loosening areas in these homogenous structures, to generate a meaningful density and to avoid urban sprawl.

\section{REFERENCES}

[1] Hönger, Christian/ Brunner, Roman/ Wieser, Christoph (2009): Das Klima als Entwurfsfaktor, Einfach Komplex. Lösungswege. In: Hochschule Luzern, Technik \& Architektur, Unruh, Tina (ed.): Das Klima als Entwurfsfaktor. Luzern: Quart Verlag GmbH, 10:39

[2] Krausse, Joachim (1995): Das Haus entwickelt sich also vom Maschinenparadigma zu einem organischen Paradigma. In: ARCH+ Nr. 126 (Solare Architektur). Aachen : 23

[3] Suartika, Gusti Ayu Made (2013): Vernacular Transformation. Architecture, place and tradition. Denpasar: Pustaka Larasan

[4] Davison, Julian (1999): Balinese architecture. Singapore: Periplus Editions (HK) Ltd. 